Solhdju • Vedder (Hg.)

Das Leben vom Tode her 


\section{TRAJEKTE}

\section{Eine Reihe des Zentrums für Literatur- und Kulturforschung Berlin}

Herausgegeben von

Sigrid Weigel und Karlheinz Barck ( $\dagger$ ) 
Katrin Solhdju • Ulrike Vedder (Hg.)

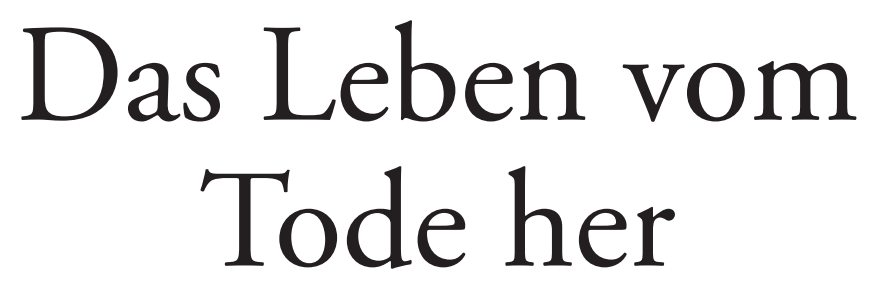

Zur Kulturgeschichte einer Grenzziehung

Wilhelm Fink 
Die Drucklegung dieses Bandes wurde vom Bundesministerium für Bildung und Forschung unter dem Förderkennzeichen 01UG1412 gefördert.

\author{
Umschlagabbildung: \\ Hugo Simberg, The Garden of Death, 1896, \\ watercolour and gouache on paper, glued on etchingspaper, $15,8 \times 17,5 \mathrm{~cm}$, \\ Ateneum Art Museum, Finnish National Gallery/Jouko Könönen
}

Bibliografische Information der Deutschen Nationalbibliothek

Die Deutsche Nationalbibliothek verzeichnet diese Publikation in der Deutschen

Nationalbibliografie; detaillierte bibliografische Daten sind im Internet über http://dnb.d-nb.de abrufbar.

Alle Rechte, auch die des auszugsweisen Nachdrucks, der fotomechanischen Wiedergabe und der Übersetzung, vorbehalten. Dies betrifft auch die Vervielfältigung und Übertragung einzelner Textabschnitte, Zeichnungen oder Bilder durch alle Verfahren wie Speicherung und Übertragung auf Papier, Transparente, Filme, Bänder, Platten und andere Medien, soweit es nicht $\$ \$ 53$ und 54 UrhG ausdrücklich gestatten.

(C) 2015 Wilhelm Fink, Paderborn

(Wilhelm Fink GmbH \& Co. Verlags-KG, Jühenplatz 1, D-33098 Paderborn)

Internet: www.fink.de

Einbandgestaltung: Evelyn Ziegler, München

Printed in Germany.

Herstellung: Ferdinand Schöningh GmbH \& Co. KG, Paderborn

ISBN 978-3-7705-5746-2 


\title{
Auferweckung als Programm. \\ Entgrenzungen des Lebendigen in der russischen Moderne
}

\author{
„Pruschewski! Wird es der Wissenschaft mit ihren \\ Errungenschaften gelingen, die Toten wiederzuerwe- \\ cken, auch wenn sie längst vermodert sind?“ \\ „Nein“, sagte Pruschewski. \\ „Lüge!“ mischte sich Shatschew ein, ohne die Augen \\ zu öffnen. „Der Marxismus kann alles. Wozu liegt \\ denn Lenin in Moskau, heil und ganz? Weil er auf \\ die Wissenschaft wartet und auferstehen will. [...]" \\ Andrej Platonov, Die Baugrube ${ }^{1}$
}

In Vladimir Sorokins Roman Ljod. Das Eis $(\text { Led, 2002) })^{2}$ wird das bis heute ungeklärte Tunguska-Ereignis von 1908, bei dem eine Detonation ein riesiges Territorium in Nordsibirien verwüstete, literarisch gedeutet: Kosmisches Eis sei auf die Erde niedergegangen und solle dazu dienen, die 23000 Mitglieder einer „Bruderschaft des Lichts“ zu finden, die unter ,leblosen“ Menschen, Fleischmaschinen, leben und deren Herzen sich in einem Schlafzustand befinden. Um Fleisch von Licht zu scheiden, greifen Sorokins Erwecker auf eine brachiale Methode zurück: Aus dem Tunguska-Eis werden Hammer gefertigt, mit denen sie die Brustkörbe potentieller Brüder und Schwestern ,wachklopfen'. Nur die Herzen der Lichtmenschen überleben diese Prozedur und sprechen, derart erweckt, ihren wahren Namen aus. Die Bruderschaft lebt zölibatär und vegan; sie kommuniziert untereinander durch die Vereinigung der Herzen und nach außen - auf der Suche nach ihresgleichen - mit der eisigen Gewalt des Ljod-Hammers. Am Ende des Romans arbeitet sie, analog zu den neuesten technologischen Entwicklungen, mit einer modernisierten und dem Lifestyle angepassten flächendeckenden Methode: Für die eigenhändige häusliche Anwendung der Erweckungstechnik werden gezielt Ljod-Wellness-Sets inklusive Brusthammer versendet. Beigelegt sind Erleuchtungsberichte zufriedener Kunden, die sich in einer virtuellen Simulation im Reigen der wieder-

1 Andrej Platonov: Kotlovan (1929), dt. Andrej Platonow: Die Baugrube, in: ders.: Die Baugrube. Das Juvenilmeer. Dshan: Romane, aus dem Russischen von Alfred Frank und Werner Kaempfe, Berlin 1989, S. 5-166, hier S. 133.

2 Der Roman bildet zusammen mit den Bänden Bro und 23000 den chronologisch zweiten Teil einer Romantrilogie. Ljod. Das Eis wurde 2005 als „Kollektives Lesen eines Buches mit Hilfe der Imagination" von Alvis Hermanis (Schauspiel Frankfurt) inszeniert; vgl. http://www.stagemediaproduction.de/beispiel_koll.html [letzter Zugriff am 26.2.2014]. 
vereinten 23000 Lichtmenschen sehen und fortan die Vision der Weltauflösung im kosmischen Licht teilen.

Diesem skurrilen literarischen Szenario kann ein nicht weniger merkwürdiges Beispiel aus der russischen Wirtschaft zur Seite gestellt werden, das ebenfalls eine neue Form der Vitalität im Zeichen der Kälte (griech. k@v́os) entwirft: das 2006

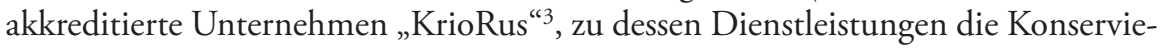
rung von Gehirnen und Körpern in flüssigem Stickstoff gehört, um diese zu einem künftigen Zeitpunkt aufzuerwecken. Ganz im Geiste des Transhumanismus, jener philosophischen Denkrichtung also, die den Einsatz neuer Technologien zur Veränderung des Lebens und damit auch der menschlichen Spezies befürwortet, geht die Kryonik davon aus, dass die heutige Definition vom medizinischen Tod, der Gehirntod, mit fortschreitender Technik ihre Gültigkeit in der Zukunft verlieren werde - analog zur Einführung der Herz-Lungen-Maschine, mit der sich das Herztodkriterium als unzureichend herausstellte. Die Kryonik präpariert den zahlungswilligen Klienten für den Moment, da eine Verpflanzung von Gehirnen und eine Wiederbelebung von Körpern sowie die Heilung der Ursachen, die zur Stagnation der Lebensfunktion geführt haben, technisch möglich sein werden. Ziel ist es also, jenen Zersetzungserscheinungen entgegenzuwirken, die mit traditionellen Bestattungsformen verbunden sind und die deanimierten Organe und Körper bei tiefen Temperaturen in einem quasi-lebensfähigen Zustand aufzubewahren, kurzum: Leben auf Eis zu legen. Mit der vergleichsweise preisgünstigen Neurosuspension, die den ,Patienten“von „KrioRus“ um die 10000 Euro kostet, sollen die im Gehirn gespeicherten Informationen haltbar gemacht werden. Trotz der grundlegenden Einwände seitens der Kryobiologie ${ }^{4}$ ist man davon überzeugt, dass die in KrioTanks aufbewahrten Gehirne in der Zukunft aufgetaut und in einen neuen Körper verpflanzt werden können. Mit dieser Spekulation ist die Sehnsucht nach einer Epoche der Langlebigkeit oder gar Unsterblichkeit verbunden; ${ }^{5}$ in der Sprache der Kryoniker aber ist der Tod bereits jetzt eliminiert.

Beide Beispiele sind symptomatisch für Russland zu Beginn des 21. Jahrhunderts, zeigen sie doch einflussreiche weltanschauliche und technologische Tenden-

3 Vgl. die Webseite des Unternehmens unter http://www.kriorus.ru [letzter Zugriff am 26.2.2014]. Bis dahin wurden Tote nur in den USA durch die Alcor Life Extension Foundation und das Cryonics Institute in Kryostase versetzt; die erste Suspension fand am 12. Januar 1967 an James Bedford statt. Im Vorfeld bezogen die Begründer dieser Gesellschaft in philosophischen Schriften Stellung, etwa der Alcor-Chef Robert Ettinger in The Prospect of Immortality (1962). Vgl. dazu, auch aus theologischer Perspektive, Oliver Krüger: „Die Aufhebung des Todes. Die Utopie der Kryonik im Kontext der US-amerikanischen Bestattungskultur“, in: Thomas Macho/Kristin Marek (Hg.): Die neue Sichtbarkeit des Todes, München 2007, S. 211-228.

4 Trotz neuer Methoden wie beispielsweise der Vitrifikation (Kälteverglasung), die Zellschäden durch Kristallbildung verhindert, bleibt die Kryokonservierung, also das Einfrieren, Lagern und Auftauen von biologischem Material, eine technische Herausforderung der Zellbiologie; vgl. Sabine Schmitz: „Kryokonservierung und Langzeitlagerung von Zellen“, in: dies.: Der Experimentator: Zellkultur, München 2007, S. 176-189.

5 Vgl. die Unsterblichkeitsplattform russischer Anhänger des Transhumanismus und Immortalisten unter http://www.bessmertie.org [letzter Zugriff am 26.2.2014]. 
zen in der Bevölkerung eines Landes auf, das sich nach einer gescheiterten Utopie neu orientieren muss. Das kommerzialisierte transhumanistische Labor als Station auf dem Wege zur Immortalität und die in Sorokins Roman parodierte Bio-Spiritualität erweckter Menschen sind dabei zwei Komponenten im Spektrum moderner Erweckungsrituale, die nicht erst heute Konjunktur haben. Vielmehr sind es Echos einer diskursiven Praxis und Rhetorik der (geistigen und körperlichen) Auferweckung, die vor dem Hintergrund des allgemeinen Krisenbewusstseins um 1900 die russische Kultur maßgeblich zu dominieren beginnt und nun um die Jahrtausendwende erneut auflebt.

Mein Beitrag geht diesem russischen Interesse an Vitalität und Transformation im ersten Drittel des 20. Jahrhunderts nach. Dabei rücken insbesondere kulturspezifische Unterschiede zu vergleichbaren Phantasmen und Phänomenen in Westeuropa ins Blickfeld, die sich aus der Berücksichtigung der ostkirchlichen Tradition, insbesondere der orthodoxen Anthropologie, ergeben. ${ }^{6}$ Das Auferweckungsparadigma der russischen Moderne zeichnete sich zum einen durch seine Doppelreferenz auf Religion und Wissenschaft aus und manifestierte sich zum anderen durch die Synthese von Glauben und Technik, Kunst und Leben. Wie es zunehmend den russischen und sowjetischen Alltag durchdrang, wird anhand folgender Faktoren nachvollzogen: der Begründung der genuin russischen religionsphilosophischen Strömung des „Kosmismus"7, der aufkommenden performanzorientierten Konzepte des Lebendigen in Sprach- und Literaturtheorie und schließlich der Versuchsanordnungen zur Vitalisierung und Immortalisierung in Wissenschaft, kultureller Praxis und Literatur.

\section{Am Anfang war der Körper}

Die posthum unter dem Titel Philosophie des gemeinsamen Werks (Filosofija obščego dela, 1906/1913) erschienene Lehre des als ,Moskauer Sokrates'verehrten Bibliothekars Nikolaj Fedorov (1823-1903) hat in Russland eine erstaunliche Rezeptions-

6 Die Schlüsselfunktion des Todes auf dem Weg vom Vergänglichen zum Ewigen und vom Menschlichen zum Göttlichen, deren Imagination eng mit dem Nachleben entsprechender ägyptischer und griechischer Vorstellungen im Christentum verbunden ist, gilt für Ost und West und weist in der patristischen bzw. frühbyzantinischen Periode, so der Kirchenhistoriker Gerhard Podskalsky, kaum Differenzen auf (vgl. Gerhard Podskalsky: „Tod und Auferstehung in der byzantinischen Theologie“, in: Zeitschrift für katholische Theologie, 122 (2000), S. 14-33). Bei den Diskursivierungen von Leben und Tod in der russischen Moderne sind dagegen spätere Konzepte der orthodoxen Theologie und der russischen Religionsphilosophie grundlegend.

7 Vgl. die Kanonisierung durch Svetlana G. Semenova/Anastasija G. Gačeva (Hg.): Russkij kosmizm. Antologija filosofskoj mysli, Moskau 1993, sowie zum Kosmismus als Formel einer neuen russischen Eschatologie Michael Hagemeister: „Nikolaj Fedorov und der ,russische Kosmismus““, in: Franz Josef Klehr/Eberhard Müller (Hg.): Russische religiöse Philosophie. Das wiedergewonnene Erbe: Aneignung und Distanz, Stuttgart 1992, S. 159-170, und ders.: „Russian Cosmism in the 1920s and Today", in: Bernice G. Rosenthal (Hg.): The Occult in Russian and Soviet Culture, Ithaka 1997, S. 185-202. 
geschichte erfahren. Darin wurde eine Neue Menschheit postuliert, die sich für das sogenannte "gemeinsame Werk" (obščee delo) verbrüdern soll, welches auf nichts Geringeres zielt als auf die Auferweckung der Toten. Dem Tun dieser weltumfassenden Erweckungsgemeinschaft, die der Wiederbelebung der Toten und der Erschließung des Kosmos als Lebensraum für diese verpflichtet ist, legte Fedorov ein traditionelles Liturgie-Verständnis zugrunde, das nicht nur die organische Gesamtheit gottesdienstlicher Kultur, sondern eben auch die Bedeutung von $\lambda \varepsilon \iota \tau o v \varrho \gamma i ́ \alpha$ als ,öffentlicher Dienst' oder ,Gemeinschaftswerk ${ }^{6}$ einschloss. ${ }^{8}$ Dieses bildete das Modell für die gesamtgesellschaftliche Kooperation im Dienst an der Gemeinschaft.

Um die künstlerisch-schöpferische und wissenschaftlich-technische Tätigkeit zu vereinen, sollte die Theologie den „Erziehungsrahmen“ für die Wissenschaften bilden, letztere zu ,geistigen, einen heiligen Dienst verrichtenden Organen“ werden und die Wissenschaftler selbst „zum Klerus“. ${ }^{9}$ Die Wissenschaft, allen voran die Experimente der Physiologie - beispielsweise die Verjüngungsexperimente ${ }^{10}$ des Franzosen Charles Edouard Brown-Séquard (1817-1894) und die Wiederbelebungsversuche am menschlichen Herzen, die Aleksej A. Kuljabko (1866-1930) erstmalig im Jahre 1902 gelangen $^{11}$-, lieferten für Fedorov bereits Beweise für die zukünftige Realisation der physischen Auferweckung im lebensweltlichen Aktionsraum. Er führte auch die visionären Entwürfe von Luftschiffen und Luftschiffnetzen an, die der Gelehrte und Staatsmann Vasilij N. Karazin (1773-1842) zur Klimaregulation sowie zur Nutzbarmachung atmosphärischer Elektrizität entwarf. Diese Apparatur galt es in den Dienst der Auferweckung zu stellen: zur Einwirkung

8 Dabei sollten Gottesdienst, die „kirchliche Liturgie“ (chramovaja liturgija), und das Leben, die „außerkirchliche Liturgie“ (vnechramovaja liturgija), letztere auch eine „Liturgie des Brüderschaffens“ (liturgija bratotvorenie), wieder in Einklang gebracht werden; vgl. Nikolaj F. Fedorov: „Vopros o bratstve, ili rodstve, o pričinach nebratskogo, nerodstvennogo, t. e. nemirnogo, sostojanija mira i o sredstvach k vosstanovleniju rodstva", in: ders.: Sobranie sočinenij v četyrech tomach, Bd. 1, Moskau 1995, S. 35-308, hier S. 89, 119 u. passim. Zu Fedorovs Liturgie-Verständnis vgl. auch Valentin A. Nikitin: „Der Kultakt als Synthese der Künste. Theoretische Überlegungen von Priester Pawel Florenski und Nikolai Fjodorow zur orthodoxen Sakralkunst", in: Stimme der Orthodoxie 11 (1988), S. 29-36.

9 Nikolaj F. Fedorov: „Das Museum, sein Sinn und seine Bestimmung“ (Auszug), in: Boris Groys/ Michael Hagemeister (Hg.): Die Neue Menschheit. Biopolitische Utopien in Russland zu Beginn des 20. Jahrhunderts, aus dem Russischen von Dagmar Kassek, Frankfurt a. M. 2005, S. 127-232, hier S. 213.

10 Weiterführend dazu Heiko Stoff: Ewige Jugend. Konzepte der Verjüngung vom späten neunzehnten Jahrhundert bis ins Dritte Reich, Köln 2004.

11 Vgl. Nikolaj F. Fedorov: „Vnutrennjaja reguljacija, ili preobraženie živuščih, synov, i pervoe voskrešenie umeršich, otcov, i pervoe voznesenie ich na inye miry (planety) dlja rasširenija vnešnej reguljacii, a s neju dal'nejšich voskrešenij ili svjaščennodejstvij, kak vyraženie supramoralizma“, in: ders.: Sobranie sočinenij v četyrech tomach, Bd. 3, Moskau 1997, S. 355-359, hier S. 358. Die Reanimationsversuche Kuljabkos und nachfolgender Experimentatoren geben, so Fedorov, auch den Impuls für eine praktische Lösung der Wiederbelebungsfrage, die auf die Umgestaltung von Friedhöfen in Krankenhäuser ziele; vgl. Nikolaj Fedorov: „Kreml' kak krepost' i orudija reguljacii umerščlljajuščej sily i kreml’ kak kladbǐ̌če i popytki oživlenija“, in: ders.: Sobranie sočinenij, Bd. 3 (Anm. 11), S. 359-360, hier S. 359. 
auf Leichname, zu Forschungszwecken und zur Reanimation, um dem allgemeinen Auferweckungsprojekt den Weg zu bahnen. ${ }^{12}$

Fedorovs Projekt und die darin integrierten biotechnologischen, meteourgischwettersteuernden und raumfahrttechnischen Aufgaben, die für den russischen Kosmismus grundlegend sind, standen durch den maßgeblichen gemeinschaftsbildenden bzw. liturgischen Faktor im Gegensatz zu anderen wissenschaftlich-technischen Entwürfen und Technologiephantasmen seiner Zeit. Die Technologien der Zukunft sollten allein zur Wiederbelebung einer auf Ahnenkult beruhenden religiösen Praxis dienen, ${ }^{13}$ der ein auf den Kopf gestelltes Verständnis von Erbschaft zugrunde lag: Solange Söhne ihr Leben durch Geburt empfingen, anstatt es selbst zu schaffen, erbten sie eine Pflicht - die Pflicht zur Auferweckung ihrer Väter. Wie dieses Erbe anzutreten ist, scheint in der russischen Sprache selbst verankert zu sein: Die lexikalische Wurzel von nasledstvo (Erbe, Erbschaft, Vererbung) ist sled (Spur). ,Auferweckung 'hieß bei Fedorov das mechanisch-materialistische Aufspüren, Sammeln und Klassifizieren sowie die Synthese und Wiederbelebung der Spuren der Verstorbenen, von Staub und Teilchen der Ahnen. Fedorovs „kosmotellurische Wissenschaft und Kunst " ${ }^{114}$ führte wissenschaftlich-analytische und künstlerisch-synthetische Methoden als einander ergänzende Kräfte des Versammelns zusammen. ${ }^{15}$ Die WissenschaftKunst der Auferweckung beschrieb ein zweistufiges Verfahren, das im ersten Schritt die Beschaffung und das Lesen der gesammelten Information als männliche Aufgabe vorsah, und im zweiten Schritt, als weiblich-künstlerische Aufgabe, die Synthese - das Zusammensetzen (složenie) und Zusammennähen (š̌ivanie).

Fedorovs Lehre radikalisierte nicht nur die existentielle Leitfrage nach den Grenzen zwischen Leben und Tod bzw. Sterblichkeit und Unsterblichkeit, sie entgrenzte auch die mystisch-tellurische Vorstellung von der Entstehung des Menschen aus dem Staub der Erde, in den er - ein Zeichen der Ursünde - zurückkehren muss. Gemäß der ostchristlichen Theologie, die keine ausdrückliche Erbsündenlehre kennt und die Lehre vom Purgatorium ablehnt, ${ }^{16}$ waren es einzig Krankheit und

12 Vgl. Fedorov: „Vopros o bratstve“ (Anm. 8), S. 259. Vgl. auch Wolfgang Eismann: „Technischer Fortschritt und Wiedererweckung der Toten. Eine russische Utopie im Kontext russischer universalistischer Denktradition", in: Götz Pochat/Brigitte Wagner (Hg.): Utopie. Gesellschaftsformen, Künstlerträume, Graz 1996, S. 169-185.

13 Vgl. Fedorov: „Vopros o bratstve“ (Anm. 8), S. 69, ders.: „Religija - kul't predkov i voskrešenie“, in: ders.: Sobranie sočinenij v četyrech tomach, Bd. 2, Moskau 1995, S. 42-44.

14 Vgl. Fedorov: „Vopros o bratstve“ (Anm. 8), S. 290. Diese Bezeichnung ist ein Hinweis auf die philosophische Verschränkung des orthodox-christlichen energeia-Verständnisses mit physikalischen Energiekonzepten, wie sie beispielsweise Theodor Hoh in Elektricität und Magnetismus als kosmotellurische Kräfte (1887) darlegte.

15 Die Aufhebung des Widerspruchs zwischen Kunst und Wissenschaft ist Voraussetzung für die Realisation des Auferweckungsprojekts; vgl. Nikolaj F. Fedorov: „Kak možet byt' razrešeno protivorečie meždu naukoju i iskusstvom?"“, in: ders.: Sobranie sočinenij, Bd. 2 (Anm. 13), S. 233235.

16 Das Fehlen einer neutralen Sphäre, die das Fegefeuer als Zwischenstadium zwischen Gut und Böse verkörpert, hat die Kultursemiotiker Lotman und Boris Uspenskij 1977 veranlasst, Russland ein dualistisch-bipolares Kulturmodell zugrunde zu legen. Das Zwei-Sphären-Modell in der altrussischen Kultur begründet demzufolge nicht nur das axiologische Entweder-Oder (Himmel/Hölle; 
Tod, in denen sich die Vererblichkeit der Ursünde manifestierte und die es nun mit Hilfe von Wissenschaft und Technik zu überwinden galt. ${ }^{17}$ Das Ziel der von Fedorov entworfenen Kosmotellurgie, der künstliche, synthetisierte Körper, scheint dabei Informations- und Reproduktionstechnologien der Zukunft zu antizipieren. Gemäß der Losung „,unser Körper muss unser Werk sein “18 sollte der Mensch lernen, seinen Körper selbst zu konstruieren und seinen Organismus zu vervollkommnen, indem er Organe schafft, die neue Fähigkeiten verkörpern und die Vitalität stärken. ${ }^{19}$ Der naturgegebene Körper - ein „Werk der blinden und unbewussten Evolution " 20 - sollte radikal umgestaltet und im Prozess der kosmotellurischen Patrofikation, der Kunst des Väterschaffens (otcetvorenie), als buchstäbliches KunstWerk (chudožestvennoe proizvedenie) neu belebt werden. Das liturgische Handeln sei aber nicht auf eine „übermenschliche " und „unsterbliche “ Kreatur gerichtet, ${ }^{21}$ sondern auf eine Neue Menschheit, die durch ein neues, geschlechtsneutrales Bruderschafts- bzw. Verwandtschafts- und Sozialsystem, durch die res fratria, vereint sei und eine „psychokratische“ Gesellschaftsform begründe. ${ }^{22}$

sündig/heilig), sondern setzt sich im Hinblick auf gesellschaftliche Dynamiken als permanente Umkehrung von Neuem/Alten fort; vgl. Jurij Lotman/Boris Uspenskij: „Die Rolle dualistischer Modelle in der Dynamik der russischen Kultur (bis zum Ende des 18. Jahrhunderts) “, in: Poetica, 9 (1997) 1, S. 1-40, hier S. 3. Der Konstanzer Slawist Igor' P. Smirnov (vgl. O drevnerusskoj kul'ture, russkoj nacional'noj specifike i logike istorii, Wien 1991, S. 45 Anm. 68) verweist auf die Vorstellung von den mytarstva (russ. Qualen). Letztere beschreiben in apokryphen Schriften den Leidensweg, den die Seele nach dem Tode, von Dämonen begleitet, zu Gottes Thron zurückzulegen hat. Diese Vorstellung ist nicht Bestandteil der orthodoxen Dogmatik, die abweichende Positionen entschieden ablehnt, etwa die von Seraphim Rose, einem orthodoxen Priestermönch in den USA, in: Die Seele nach dem Tod. Heutige "Nach-Todes"-Erfahrungen im Licht der orthodoxen Lehre vom Leben nach dem Tod, München 1999.

17 Im Grunde unternimmt Fedorov eine Re-Lektüre der Bibel und macht u.a. die Worte „Gott ist nicht Gott von Toten, sondern von Lebendigen“ zum Gebot; vgl. Lev Zander: „Technik und Glaube. Eine Skizze aus russischer Religionsphilosophie“, in: Studium Generale 16 (1962) 5, S. 324-334, hier S. 327-329. Zur Verschränkung von technischem Fortschrittsglauben und orthodoxer Eschatologie auf dem Weg zu einer, Neuen Menschheit' bei Fedorov und dessen Anhängern vgl. insbesondere die historisch-kontextualisierende Studie von Michael Hagemeister: Nikolaj Fedorov. Studien zu Leben, Werk und Wirkung, München 1989, sowie Maja Soboleva: „Nikolaj Fedorovs ,Philosophie der gemeinsamen Tat' im Lichte der modernen Bioethikdiskussion“, in: Zeitschrift für Slavistik, 48 (2003) 1, S. 29-37, die Fedorovs Philosophie vor dem Hintergrund aktueller biomedizinischer Entwicklungen betrachtet.

18 Vgl. Fedorov: „Vopros o bratstve“ (Anm. 8), S. 82.

19 Ebd., S. 255.

20 Nikolaj F. Fedorov: „Bessmertie kak privilegija sverchčelovekov (Po povodu stat'i V. S. Solov’eva o Lermontove)“, in: ders.: Sobranie sočinenij, Bd. 2 (Anm. 13), S. 136-140, hier S. 138.

21 Vgl. Fedorov: Bessmertie kak privilegija sverchčelovekov (Anm. 20); zur Diskussion von Übermenschheit und Unsterblichkeit, wie sie zu Lebzeiten und in der Nachfolge Fedorovs geführt wurde, insbesondere zu den Divergenzen und Konvergenzen dieser Konzepte im gesellschaftlichen Wandel, vgl. Ernst Benz (Hg.): Der Übermensch. Eine Diskussion, Zürich 1961; Gottfried Küenzlen: Der Neue Mensch. Eine Untersuchung der säkularen Religionsgeschichte der Moderne, München 1994.

22 Vgl. Nikolaj F. Fedorov: „Muzej, ego smysl i naznačenie“, in: ders.: Sobranie sočinenij, Bd. 2 (Anm. 13), S. 370-430, hier S. 383; ders.: „Vopros o bratstve“ (Anm. 8), S. 44. 
Fedorovs aisthetisch-korporale/r Erweckungskult/ur ist in der orthodoxen Ekklesiologie verankert, welche die auf den Gottmenschen gerichtete Christologie fortschreibt: Die Kirche verkörpert den Leib Christi, einen lebendigen, gottmenschlichen Organismus, in dem die Lebenden und die Toten integriert sind. In analoger Weise sah Fedorov als Vorbild für eine kultische Institution, die den Staub der Vorfahren heiligen, erforschen und synthetisieren könnte, den Moskauer Kreml. Die ursprüngliche Friedhofs-Festung könne nunmehr Schule und Forschungsstätte, Laboratorium und Observatorium, Museum und Gotteshaus in einem sein. Dieser Vorschlag scheint darauf abzuzielen, die Kirche bzw. das orthodoxe Körperkonzept in seiner anthropologischen und sozialen Dimension institutionell in der modernen Wissen(schaft)sgesellschaft zu verankern. Dabei wurde dem Menschen eine neue Rolle zuerkannt, die zum einem aus der erforderlichen Vereinigung von religiös-schöpferischer und wissenschaftlich-technischer Tätigkeit erwuchs. Zum anderen erinnerte sie an die ursprüngliche Rolle des Christen, an

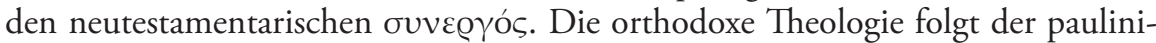
schen Tradition und nimmt die Getauften als „Gottes Mitarbeiter“ (I Kor 3,9; russ.

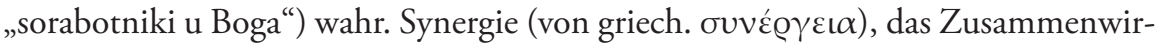
ken menschlicher und göttlicher Energien, ${ }^{23}$ bildet hier den Kerngedanken der $\theta \varepsilon ́ \omega \sigma \iota \varsigma$, der Vergöttlichung des Menschen im Erlösungsprozess. Der Mensch nimmt synergetisch an der göttlichen Kraft teil und wirkt so an der Gnade Gottes mit. ${ }^{24}$ Die synergetische Transformation wird demnach durch die aktive Mitwirkung (sodejstvie) des Menschen ausgelöst und führt, durch die Überwindung seiner Antinomien, zur Einheit (Synthese) in Gott. ${ }^{25}$ Im Licht der orthodoxen Synergismus-Lehre stellt sich Fedorovs kosmotellurische Praxis als synergetisches Umgestalten dar. ${ }^{26}$ Der konkreative Impuls des Menschen ließe sich wie folgt zusammenfassen: An die Stelle der nunmehr als passiv markierten Auferstehung (voskresenie) tritt die aktive, durch die liturgische Gemeinschaft initiierte Auferweckung (voskrešenie).

23 Die orthodox-byzantinische Theologie folgt hier Gregorios Palamas, der mit ,Energie‘ die Wirkkraft Gottes bezeichnete - im Unterschied zu dessen unerkennbaren Substanz.

24 Vgl. Konrad Onasch: Einführung in die Konfessionskunde der orthodoxen Kirchen, Berlin 1962, S. 231-237.

25 Religionsphilosophische Konzepte der russischen Moderne implizieren diesen Grundsatz, allen voran Aleksej S. Chomjakovs Konzept der harmonischen Kirchengemeinschaft (sobornost') sowie Vladimir S. Solov'evs Lehre von der Alleinheit (vseedinstvo) und dem Gottmenschentum (bogočelovečestvo).

26 Vgl. dazu Sergej Bulgakov: „Zagadočnyj myslitel’ (N. F. Fedorov)“, in: ders.: Dva grada, Bd. 2, Moskau 1911, S. 260-277; Nikolaj Berdjaev: „Religija voskrešenija. ,Filosofija obščego dela“ N. F. Fedorova“, in: Russkaja mysl', 36 (1915) 7, S. 75-120. 


\section{Aisthetisierung des Logos}

Fedorov, der das kosmotellurische KunstWerk mit großen Dichtungen verglich, denen der Plan zur Veränderung des Lebens innewohne, ${ }^{27}$ sah in der Ästhetik eine Wissenschaft von der „Wiederherstellung“ (vossozdanie) des Vergangenen. Von dieser gehe auch der schöpferische Impuls der Auferweckung aus. ${ }^{28}$ Grundlage für die Neuerschaffung des Lebens sei die mediale Synthese der Künste in der Kirche. ${ }^{29}$ Die organische Geschlossenheit verleihe der Kunst die Kraft, sich der Erdanziehung entgegenzustellen, Chaos in Kosmos zu transformieren, die Friedhof-Erde in einen Himmel-Lebensraum umzugestalten. ${ }^{30}$

Der Religionsphilosoph und Dichter Vladimir S. Solov'ev (1853-1900), der die Ideen seines Gesprächspartners Fedorov schätzte, fügte der Vorstellung von einer schöpferischen Synthese den Gedanken der antiken Theurgie ${ }^{31}$ hinzu, den er zu einem Handlungs- und Organisationsmodell der Gottwerdung weiterentwickelte, das sich als aktives ,Umschaffen' (pretvorenie) des Menschen in der Synthese von Religion, Technik und Kunst realisieren sollte. In der Folge betonte der Religionsphilosoph Nikolaj A. Berdjajev (1874-1948) in seinem Buch Der Sinn des Schaffens: Versuch einer Rechtfertigung des Menschen (Smysl tvorčestva: opyt opravdanija čeloveka, 1916), dass durch die Theurgie „neues Sein“ geschaffen werde: „In der Theurgie wird das Wort Fleisch." Mit der theurgischen Kunst ende das herkömmliche Menschenwerk, denn es sei ,gemeinschaftliche[s] Wirken des Menschen mit Gott" und damit „Gott-Wirken, gottmenschliches Schöpfertum“.32

Die Vorstellung vom synergetisch-theurgischen Schöpfungsakt in der Synthese der Künste beeinflusste das russische Denken des ,Silbernen Zeitalters ${ }^{33}$ maßgeblich. Die Kunst wurde zur Vermittlerin zwischen Natur und künftigem Leben. Als

27 Vgl. Nikolaj F. Fedorov: „Muzej, ego smysl i naznačenie“ (Anm. 22), S. 399.

28 Vgl. ders.: „Isskustvo podobij (mnimogo chudožestvennogo vosstanovlenija) i iskusstvo dejstvitel'nosti (dejstvitel'noe voskrešenie)“, in: ders.: Sobranie sočinenij, Bd. 2 (Anm. 13), S. 230-231, hier S. 231.

29 Diese stehe im Gegensatz zum säkularen Gesamtkunstwerk, das nur Untergang und Verderben darstelle, so Fedorovs Kritik an Arthur Schopenhauer, Richard Wagner und Friedrich Nietzsche; vgl. Nikolaj F. Fedorov: „Tragičeskoe i vakchičeskoe u Šopengauera i Nicše (1913)“, in: ders.: Sobranie sočinenij, Bd. 2 (Anm. 13), S. 159-160; ders.: „Ob ob”edinenii iskusstv (1913)“, in: ebd., S. $160-161$.

30 An Fedorov anknüpfend, entwarf der Maler Vasilij N. Čekrygin (1897-1922) eine Kunsttheorie der Auferweckung als einer Synthese der lebendigen Künste: $O$ Sobore voskrešajuščego museja. $O$ budǔ̌cem iskusstve: muzyki, živopisi, skul'ptury i slova (Die Kathedrale des auferweckenden Museums. Die Kunst der Zukunft: Musik, Malerei, Skulptur und das Wort), Moskau 1921; vgl. auch Wassili Rakitin: Tschekrygin, Mystiker der russischen Avantgarde. Aus der Geschichte des russischen Expressionismus. Ausstellungskatalog, Köln 1992.

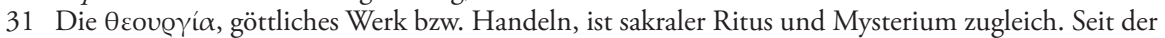
Spätantike wird darunter die Kunst verstanden, mittels bestimmter Verfahren in direkten Kontakt mit dem Göttlichen zu treten, um den Menschen das Erkennen göttlichen Wirkens und letztlich auch die Vereinigung mit dem göttlichen Wesen zu ermöglichen.

32 Nikolaj Berdiajew: Der Sinn des Schaffens: Versuch einer Rechtfertigung des Menschen, aus dem Russischen von Reinhold von Walter, Tübingen 1927, S. 263.

33 Höhepunkt in der russischen Literatur der ersten beiden Dezennien des 20. Jahrhunderts. 
Trägerin theurgischer Kräfte trat sie als Erneuerungsinstanz der Welt auf - im lebensschaffenden Konzept der Symbolisten (žiznetvorčestvo) ebenso wie im avantgardistischen lebensbauenden Prinzip (žiznestroenie). ${ }^{34}$ Ihr kunstreligiöser Anspruch kommt am deutlichsten im Theorem der Auferweckung zur Geltung, das bei den Vertretern unterschiedlicher literarischer Strömungen und in der sprachphilosophischen Essayistik dieser Zeit vom Aufleben religiöser Sprachwirkungskonzepte zeugt. ${ }^{35}$

Beispielsweise bezeichnete der Symbolist Andrej Belyj (1880-1934) in seinem Essay Die Magie der Worte (Magija slov, 1909) das alltagssprachliche Wort als einen „stinkenden, sich zersetzenden Leichnam“. ${ }^{36}$ Dem toten Wort setzte er das magischsymbolistische Wort entgegen, dem Bildsprache und Rhythmus, Allusionskraft und Synkretismus seine Vitalität verleihen. ${ }^{37}$ Dieses schöpferische Wort ist es, das im Symbolismus Leben schafft und die Dichtung selbst zur Lebenskunst macht. ${ }^{38}$

Der Schriftsteller und Literatur- und Filmtheoretiker Viktor B. Šklovskij (18931984) erhob 1914 für die Kunstavantgarde den Anspruch auf die Erweckung toter Formen zu neuem Leben - die „Auferweckung der Dinge“ (voskrešenie veščej) sei die Aufgabe des Futurismus. ${ }^{39}$ Am Beispiel der russischen Futuristen, deren Texte,

34 Der symbolistische Dichter und Kulturphilosoph Vjačeslav N. Ivanov (1866-1949) lehnte sich an Solov'ev an, als er davon sprach, Poesie sei kein Bilderschaffen, sondern ein „Leben-Schaffen“ (Vjačeslav N. Ivanov: Borozdy i meži. Opyty éstetičeskie i kritičeskie, Moskau 1916, Nachdruck Letchworth 1971, S. 147 f.). Der russische Formalist Nikolaj F. Čužak (1876-1937) postulierte das „Leben-Bauen“ der Literatur „Pod znakom žiznestroenija“, in: LEF, 1 (1923), S. 12-39; später wurde es zum Programm der faktographischen Literatur (vgl. Hans Günther: „Leben-Bauen“, in: Aleksandar Flaker (Hg.): Glossarium der russischen Avantgarde, Graz 1989, S. 331-337.) Die Metapher des Bauens behält ihre Bedeutung auch in der nachsymbolistischen Generation der russischen Futuristen und Akmeisten bei, sie verstärkt und konkretisiert sich sogar noch.

35 Vgl. Naftali Prat: „Orthodox Philosophy of Language in Russia“, in: Studies in Soviet Thought, 20 (1979), S. 1-21; Steven Cassedy: „Icon and Logos. The Role of Orthodox Theology in Modern Language Theory and Literary Criticism", in: Robert P. Hughes/Irina Paperno (Hg.): Christianity and the Eastern Slaves, II, Berkeley 1994, S. 311-324; Natalija Bonezkaja: „Der Kampf um den Logos im Rußland des 20. Jahrhunderts. Teil I“, in: Novalis, 2 (1998), S. 32-35, u. Teil II, in: Novalis, 3 (1998), S. 39-41. Zur Vorstellung von Sprache als Schöpfung über die Hinwendung zum Logos bis hin zum Sprachexperiment in der russischen Avantgarde vgl. Vladimir Feščenko: Laboratorija Logosa. Jazykovoj eksperiment v avangardnom tvorčestve, Moskau 2009.

36 Andrej Belyj: „Magija Slov (1909)“, in: ders.: Simvolizm kak miroponimanie, Moskau 1994, S. 131-144, hier S. 135.

37 Zur biologistischen Metaphorik der Symbolisten, stellvertretend am Beispiel Ivanovs, vgl. Gudrun Langer: Kunst, Wissenschaft, Utopie. Die „Überwindung der Kulturkrise" bei V. Ivanov, A. Blok, A. Belyj und V. Chlebnikov, Frankfurt a. M. 1990, S. 86-88.

38 Vgl. Belyj: „Magija Slov“ (Anm. 36), S. 434; zum Phänomen des Lebenschaffens in der russischen Kultur vgl. Schamma Schahadat (Hg.): Lebenskunst - Kunstleben. Žiznetvorčestvo v russkoj kul'ture XVIII-XX vv, München 1998.

39 Viktor Šklovskij: „Voskrešenie slova / Die Auferweckung des Wortes“, in: Texte der russischen Formalisten, II, hg. und mit einer Einleitung von Wolf-Dieter Stempel, München 1972, S. 2-17, hier S. 3, russ. S. 2; vgl. auch Aage A. Hansen-Löve: Der russische Formalismus. Methodologische Rekonstruktion seiner Entwicklung aus dem Prinzip der Verfremdung, Wien 1978, S. 111-113. Es handelt sich um einen frühen Essay Šklovskijs, der zu den wichtigsten Vertretern des russischen Formalismus, einer stukturalistischen literaturtheoretischen Schule (1915-1930), zählt. In späteren Texten stellt sich die Frage nach der Transformationsgewalt verstärkt aus der Perspektive poetischer Ver- 
wie religiöse Dichtung, in einer "halbverständlichen Sprache“ verfasst waren ${ }^{40}$ dem „Wort als solchem “41 huldigten und dessen sinnästhetische Qualitäten wie Klang, Rhythmus, Visualität rehabilitierten, beschrieb Šklovskij den ästhetischen Effekt des erweckten Wortes: Dort, wo das Wort von Versteinerung in Erneuerung, von Tod in Auferweckung umschlage, inkarniere die Poetik den Logos und mache ihn auf diese Weise wahrnehmbar. In Analogie zum fleischgewordenen Logos des Johannes-Evangeliums wird das nicht mehr tote Wort bzw. die lebendige Form der Dichtung zum poetischen und damit wieder fühlbaren Objekt. Šklovskij postulierte ein vitalisierendes Wirkungskonzept, das auch zu einem Grundgedanken der formalistischen Literaturtheorie avancieren sollte: „Nur das Schaffen neuer Formen in der Kunst“, heißt es bei ihm, könne „dem Menschen das Erleben der Welt zurückgewinnen, die Dinge auferwecken und den Pessimismus töten. “42 Mit anderen Worten: Eine Wiederbelebung der Dinge gemäß eschatologischer Überzeugung in poetischer Form sollte das Leben vitalisieren und die Wahrnehmung medialer Erscheinungen auf die Zukunft ausrichten. Šklovskijs künstlerischer Erweckungstechnik lag eine performanzorientierte Sprachauffassung zugrunde. Der poetischen Sprache und den formgebenden Verfahren der Literatur wurde ein hohes Wirkungs- und Handlungspotential zuerkannt. Das gleichsam erweckte und erweckende Wort sollte die ,Konversion'vom Künstler auf den Rezipienten übertragen.

Eine Kunst, die allein darauf ausgerichtet ist, die Wirkung ihrer Technik zu berechnen und ihr künstlerisch-künstliches Erweckungswerk an anderen zu vollenden, stieß bei dem akmeistischen Dichter Osip Ė. Mandel'štam (1891-1938) auf Ablehnung. In Opposition zum mystisch-verklärenden Symbolismus und zum destruktiv-schöpferischen Futurismus wandte sich der Akmeismus mit seiner Poetik des Bauens dem Ursprünglichen, Irdischen, Alltagssprachlichen zu. Es verwundert also nicht, dass Mandel'štam in der russischen Sprache selbst „fortwährende Inkarnation und Tätigkeit eines klugen und tätigen Fleisches" ${ }^{43}$ sah. Der Schriftsteller müsse an der „lebendigen Natur“ ansetzen und, mit Mandel'štams Worten, „Auferweckungsarbeit“ leisten. Nicht das Ingenieurswesen, sondern die Mäeutik des Sokrates, die Hebammenkunst, die das im Verborgenen Schlummernde behutsam ans Licht hebt, schwebte Mandel'štam wohl vor, als er dem ,Schwesternpaar Wissenschaft und Kunst Transformationsgewalt zuschrieb: „Damit eine Gegebenheit Wirklichkeit werde, muß man sie im buchstäblichen Sinne auferwecken. Genau das tut die Wissenschaft, das tut die Kunst. “44

fahren der Verfremdung (ostranenie, eigentlich: Seltsammachen) und des Gemachtseins von Texten im Allgemeinen.

40 Šklovskij: „Die Auferweckung des Wortes“(Anm. 39), S. 15.

41 Vgl. Vladimir Chlebnikov/Aleksej E. Kručenych: Slovo kak takovoe, Moskau 1913.

42 Šklovskij: „Die Auferweckung des Wortes“ (Anm. 39), S. 13.

43 Ossip Mandelstam: „Über die Natur des Wortes (1922)“, in: ders.: Über den Gesprächspartner. Gesammelte Essays 1913-1924, aus dem Russischen und hg. von Ralph Dutli, Frankfurt a. M. 1994, S. 110-131, hier S. 115.

44 Ossip Mandelstam: „Brief an die Schriftstellerin Marietta Schaginjan vom 5. April 1933“, in: ders.: Armenien, Armenien. Prosa, Notizbuch, Gedichte 1930-1933, aus dem Russischen und hg. 
Konzepte des Lebendigen sind symptomatisch für kulturtheoretische und sprachphilosophische Diskurse um 1900. In Russland stehen diese nicht allein in der Tradition der Naturphilosophie und der Vorstellung vom logostheologisch begründeten Schöpfungsakt. ${ }^{45} \mathrm{Zu}$ einem wichtigen Ausgangspunkt wird hier die mystisch-kontemplative Lehre der Namensverehrung bzw. Onomatodoxie (imjaslavie). Durch einen von orthodoxen Mönchen auf dem Athosberg hervorgerufenen theologischen Streit, ob Gott in seinem Namen selbst gegenwärtig sei, gewann diese um 1913 an Aktualität. ${ }^{46}$ Die Namensverehrer setzten Gottes Namen und Gottes Energie, in der Gottes Wesen lebendig und dadurch erfahrbar sei, gleich. Anhänger dieser Auffassung wurden vom Heiligen Synod der Russischen Orthodoxen Kirche als Häretiker verurteilt. Unter den Theologen, Philosophen und Dichtern, die dennoch Partei für die Namensverehrer ergriffen und dadurch das russische Wortschaffen im Allgemeinen maßgeblich beeinflussten, war der Mathematiker, orthodoxe Priester und Kulturtheoretiker Pavel A. Florenskij (1882-1937). Seiner Theorie des Namens legte er ein synergetisches Sprachwirkungskonzept ${ }^{47}$ zugrunde: $^{4}$ Das „Wort, der Logos - ein neuer Augenblickszustand der Wirklichkeit“" ${ }^{48}$ sei „synergetisch: Energie “49. Aus physikalischer Perspektive sei es ein Resonanzphänomen par excellence, bei dem die zusammenwirkenden Energien eine neue Qualität ergeben. ${ }^{50}$ Dies gelte auch, an Aristoteles anknüpfend, aus ontologischer Sicht, denn mit dem gegenseitigen Durchdringen von Energien entstehe "etwas Neues", eine Synergie, die "mehr [ist] als die Summe der Seinsenergie“ der sich darin offenbarenden Elemente. ${ }^{51}$ Und schließlich, vom theologischen Standpunkt aus, wirke das Wort und insbesondere der Name durch die göttliche Einwirkung in menschlicher

von Ralph Dutli, S. 141-143, hier S. 141. Der Brief ist Mandel'štams Bekenntnis zu seinem Freund Boris S. Kusin, Zoologe und Biologe, der 1933 inhaftiert wurde.

45 In Opposition zum religiösen Ontologismus der kosmotheo- und antropotheozentristisch denkenden Slavophilen standen die Redakteure der Zeitschrift Logos - Internationale Jahresschrift für Kulturphilosophie (1910-1933, Logos" - Meždunarodnyj ježegodnik" po filosofii kul'tury), die ihren philosophischen Ursprung im deutschen Neukantianismus hatte.

46 Vgl. Michael Hagemeister: „Imjaslavie - imjadejstvie. Namensmystik und Namensmagie in Rußland (1900-1930)", in: Tatjana Petzer/Sylvia Sasse/Franziska Thun-Hohenstein/Sandro Zanetti (Hg.): Namen: Benennung - Verehrung - Wirkung. Positionen in der europäischen Moderne, Berlin 2008, S. 77-98; Holger Kuße: „Von der Namensverehrung zur Namensphilosophie“, in: ders. (Hg.): Name und Person. Beiträge zur russischen Philosophie des Namens, München 2006, S. 77110.

47 Vgl. Tatjana Petzer: „Pavel und Aleksej, Narren um Christi willen. Zur psychophysischen Wirksamkeit von Namen bei Pavel Aleksandrovič Florenskij", in: dies./Sasse/Thun-Hohenstein/Zanetti: Namen (Anm. 46), S. 121-141.

48 Pawel Florenski: „Die allgemeinmenschlichen Wurzeln des Idealismus (1908)“, in: ders.: Leben und Denken, Bd. 1, aus dem Russischen von Fritz Mierau, hg. von dems./Sieglinde Mierau, Ostfildern 1995-1996, S. 169-200, hier S. 188.

49 Pawel Florenski: „Die Magie des Wortes (1920)“, in: ders.: Werke in zehn Lieferungen, Bd. 3: Denken und Sprache, aus dem Russischen von Fritz Mierau, hg. von dems./Sieglinde Mierau, Berlin 1993, S. 207-236, hier S. 222.

50 Vgl. Pawel Florenski: „Namensverehrung als philosophische Voraussetzung (1922)“, in: ders.: Denken und Sprache (Anm. 49), S. 237-290, hier S. 244 f.

51 Ebd., S. 243. 
Rede und durch die menschliche Mitwirkung an den Energien Gottes. ${ }^{52}$ Die sol-

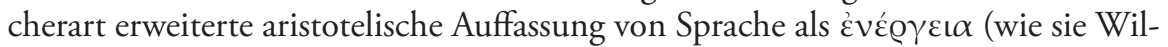
helm von Humboldt, Heymann Steinthal, Aleksandr Potebnja theoretisierten) stützte die Vorstellung von sprachmagischer Energie, mit der dem Wort Transformationsgewalt zuerkannt wurde. In den 1920er Jahren, als Fedorovs Lehre vielfach diskutiert wurde, dachte eine Gruppe Moskauer Intellektueller dessen Lehre vom "gemeinsamen Werk" mit der Auffassungen der Namensverehrer zusammen und deuteten das imjaslavie zum imjadejstvie (russ. dejstvie: Handlung, Wirkung) um, womit Wort und Tat in eins gesetzt wurden. ${ }^{53}$ In ihrer anonym veröffentlichten Schrift Todesvergottung (Smertobožničestvo, 1926) wird der aktive Kampf gegen den Tod, der, so die Verfasser, im Westen geradezu verehrt werde und den Abfall von der Liturgie und dem gemeinsamen Werk bedeute, bereits im Untertitel als ein „Kampf mit dem Wort“ (bor'ba slovom) postuliert. ${ }^{54}$ Politisch brisant wurde die Rede vom inkarnierten Logos, vom fleischgewordenen Wort, nach 1917 mit der sowjetischen Namenspolitik, als man sich bei der Verwirklichung der gesellschaftlichen Utopie die performative Wirkung von Sprache durch eine Praxis der Umbenennungen und Neuschöpfungen zunutze machen wollte. ${ }^{55}$

\section{Auferweckung im Labor}

Um 1900 machte der russische Naturwissenschaftler Porfirij I. Bachmet'ev (18601913), der nach seinem Studium in Zürich nach Bulgarien ging und von 18901907 als Professor für Physik an der Sofioter Universität lehrte, mit Beobachtungen zur Kältewirkung bei Insekten und kleinen Tieren $^{56}$ und weiterführenden Versuchen zur Unterkühlbarkeit von Fledermäusen auf sich aufmerksam. Die Untersuchungen zur Hibernation und Anabiose bei Warmblütern könnten, so die kühne Vision Bachmet'evs in seinem Beitrag „Rezept für ein Leben bis ins 21. Jahrhundert“,

52 Vgl. Florenski: „Die Magie des Wortes“(Anm. 49), S. 222.

53 Vgl. Hagemeister: Imjaslavie - imjadejstvie (Anm. 46), S. 92-96.

54 Der vollständige Titel lautet Smertobožničestvo. Koren’eresej, razdelenij i izvraščenij istinnogo učenija cerkvi. Dogmatičeskie očerki. Čast' I. Bor'ba slovom (Todesvergottung. Kern der Häresien, Spaltungen und Perversionen der wahren kirchlichen Lehre. Dogmatische Skizzen, Teil I: Der Kampf mit dem Wort); vgl. Peter Scheibert: „Die Besiegung des Todes - Ein theologisches Programm aus der Sowjetunion (1926)“, in: Gerhard Müller/Winfried Zeller (Hg.): Glaube, Geist, Geschichte. Festschrift für Ernst Benz, Leiden 1967, S. 431-447.

55 Vgl. Franziska Thun-Hohenstein: „,Dem neuen Namen Ebenbild sein‘. Andrej Platonovs Poetik des Namens und der frühsowjetische Namenskult", in: dies./Petzer/Sasse/Zanetti, Namen (Anm. 46), S. 143-164. Vom großen Interesse, das die junge Sowjetunion an sprachlichen Phänomenen zeigte, zeugt auch das Petersburger Institut des Lebendigen Wortes (Institut Živogo Slova), das von 1918-1924 bestand; vgl. Raffaella Vassena: „The Origins and Activities of Institut Živogo Slova (Petrograd, 1918-1924)“, in: Russica Romana, 13 (2006), S. 69-85.

56 Porfirij I. Bachmetjev: „Über die Temperatur der Insekten nach Beobachtungen in Bulgarien“, in: Zeitschrift für wissenschaftliche Zoologie, 65 (1899), S. 251-604; ders: Experimentelle entomologische Studien vom physikalisch-chemischen Standpunkt aus, Bd. 1: Temperaturverhältnisse bei Insekten, mit einem Vorwort von August Weismann, Leipzig 1901. 
für die Verlängerung des menschlichen Lebens und für Reisen in die Zukunft nutzbar gemacht werden. ${ }^{57}$ Damit regte der Wegbereiter der russischen Kryobiologie Phantasien über den ,anabiotischen' Menschen an.

Bachmet'ev wurde auch als Beiträger für den Fedorov gewidmeten Sammelband Universelles Werk (Vselenskoe Delo) gewonnen. Abgedruckt wurde der bereits 1899 entstandene Text „Der Sitz der Seele (Anabiose)“, der nicht nur die Grenzüberschreitung zwischen (Schein-)Tod und Leben bei Organismen beschrieb, sondern, auf der Grundlage von Analogien zwischen biologischen und anorganischen Körpern in Wachstum und Strukturbildung, auch die Frage nach der Lebendigkeit von Kristallen aufwarf und damit die Notwendigkeit fokussierte, den Lebens-Begriff zu erweitern und den Sitz der Seele neu zu bestimmen. ${ }^{58}$ Während diese Überlegungen in Sofia zur Suspension führten, zeigte die private Šanjavskij-Volksuniversität, die in Moskau von 1908 bis 1920 bestand, Interesse an Bachmet'evs Forschung und richtete eigens ein biologisches Labor ein. 1913, noch im Jahr seiner Übersiedlung nach Russland, verstarb er jedoch plötzlich, ohne seinen Wirkkreis entfalten zu können - es soll bereits Freiwillige gegeben haben, die bereit waren, sich für die Wissenschaft einfrieren zu lassen.

In den 1920er Jahren fanden Bachmet'evs Untersuchungen ihre Fortsetzung. ${ }^{59}$ Als Teil eines weiten Spektrums spekulativer und wissenschaftlicher Entwürfe verschiedener Disziplinen unterstützten derartige Experimente die Transformationsverheißungen und Unsterblichkeitsphantasmen der Sowjetmacht, die mit der Vision vom kommunistischen Neuen Menschen einhergingen. ${ }^{60}$ Wissenschaftler, Künstler und (Religions-)Philosophen arbeiteten dabei nicht nur Hand in Hand, sondern überschritten, wie die folgenden Beispiele belegen, die Grenzen zwischen Faktenwissen und Imagination. Die Entwicklungen in den Naturwissenschaften, neue Konzepte von Raum und Zeit sowie die Vorstöße in den Laboren beflügelten entsprechende Revolutionsphantasien. Die Überwindung des biologischen Todes

57 Porfirij I. Bachmet' ev: „Recept dožit' do XXI veka“, in: Estestvoznanie i geografija, 8 (1901), S. 1-13.

58 Ders.: „Sedališče duši (Anabioz”)“, in: Vselenskoe delo, Bd. 1, Odessa 1914, S. 59-85.

59 Vgl. die zeitgenössische Forschung zur Unsterblichkeit bei wenigzelligen Lebewesen und zur Wiederbelebung von Amphibien: Ivan I. Šmal'gauzen: Problema smerti i bessmertija, Moskau/Lenin$\operatorname{grad} 1926$.

60 Nietzsche wurde von allen ideologischen Lagern rezipiert und beeinflusste, gemeinsam mit Solov'ev und Marx, die Entstehung säkularreligiöser Konzepte vom Neuen Menschen und entsprechenden Kulturmythen. Der nietzscheanische Marxismus wurde unter anderem von dem Schriftsteller Maksim Gor'kij und dem Kulturpolitiker Anatolij V. Lunačarski, beides Gotterbauer, propagiert. Leo Trotzkis Vorstellungen vom Neuen Menschen verknüpften Nietzsches Vorstellungen mit Sigmund Freud und Ivan Pavlovs Reflextheorie; vgl. Hans Günther: Der sozialistische Übermensch. M. Gor'kij und der sowjetische Heldenmythos, Stuttgart/Weimar 1993; Richard Stites: Revolutionary Dreams. Utopian Vision and Experimental Life in the Russian Revolution, Oxford 1989; Bernice G. Rosenthal: New Myth, New Worlds. From Nietzsche to Stalinism, University Park, PA 2002; Léonid Heller/Michel Niqueux: Geschichte der Utopie in Rußland, aus dem Französischen von Anne Hartmann, hg. von Michael Hagemeister, Bietigheim-Bissingen 2003; Martin Schulze Wessel: „Die Konstruktion des Neuen Menschen in der sozialistischen Revolution. Wissenschaften vom Neuen Menschen im revolutionären Russland", in: Wilhelm Vossenkuhl u.a. (Hg.): Ecce Homo! Menschenbild - Menschenbilder, Stuttgart 2009, S. 66-86. 
und die Erschließung des Kosmos avancierten in der frühen Sowjetzeit zu beliebten Themen der Fortschrittsprognose in Publizistik und Literatur. ${ }^{61}$ Mit Zukunftsentwürfen, Horrorszenarien oder parodierten Sozialdramen legte man davon Zeugnis $\mathrm{ab}$, inwiefern die Visionen für möglich gehalten wurden, in die gesellschaftliche Praxis Eingang fanden, akzeptiert oder abgelehnt wurden. ${ }^{62}$

Die anarchistisch-avantgardistische Dichtergruppierung der Biokosmisten forderte eine technologische Revolution, die die Grundfesten der bürgerlichen Gesellschaft nivellieren würde: die aktive Teilnahme des Menschen am kosmischen Leben, den Sieg über den Raum und das Streben nach realer Unsterblichkeit und Auferweckung, d.h. der Wiederherstellung von Toten. ${ }^{63}$ In ihrem Manifest von 1922 heißt es: „Als wesentliche und reale Rechte des Menschen gelten für uns sein Recht auf Sein (Unsterblichkeit, Auferweckung, Verjüngung) und auf die Bewegungsfreiheit im kosmischen Raum (und nicht die vermeintlichen Rechte, die in der Deklaration der bürgerlichen Revolution von 1789 verkündigt werden). "64 Bereits vor der Revolution projektierten Anhänger des Gotterbauertums (bogostroitel'stvo) ${ }^{65}$ - einer Vereinigung von Schriftstellern, die danach strebte, christliche Vorstellungen mit dem Marxismus zu vereinen - die reale diesseitige Unsterblichkeit. Nach 1917 wurde nicht nur die gesamte Rhetorik der jungen Sowjetmacht auf eine zu erringende Unsterblichkeit ausgerichtet. Vielmehr wurden der Kampf gegen die menschliche Vergänglichkeit, die Kontrolle über das Leben sowie die Erschaffung eines organischen Kollektivkörpers, in dem das Individuum aufgeht, zum biopolitischen Programm. Die Politik der ,Neuen Menschheit', so der Medientheoretiker Boris Groys verallgemeinernd, entfaltete sich auf der Folie von Fedorovs Auferweckungsphilosophie, die Kunst und Politik, Leben und Technik, Staat und Museum radikal in eins setzte. Der sowjetische Staat übernahm - gemäß dem, was Michel Foucault über den gouvernementalen biopolitischen Zugriff herausgestellt hat, und darüber hinausgehend - die Sorge um den „unsterblichen Körper“, indem er das Leben des

61 Zum philosophiegeschichtlichen Kontext vgl. Ivan T. Frolov: „O žizni, smerti i bessmertii. Ėtjudy novogo (real'nogo) gumanizma [Über das Leben, den Tod und die Unsterblichkeit. Studien über den neuen (realen) Humanismus]", in: Voprosy filosofii, 1 (1983), S. 81-89 (Teil I) und Voprosy filosofii, 2 (1983), S. 52-64 (Teil II); Michael Hagemeister: „Zwischen Fortschrittsglauben und Endzeiterwartung. Das Problem des Todes im russischen Denken um die Jahrhundertwende“, in: ders.: Nikolaj Fedorov (Anm. 17), S. 155-187; Assen Ignatow: „Surrogate der Unsterblichkeit. Das gegenwärtige sowjetrussische Denken und das Todesproblem (1987)“, unter: www.ekd.de/ezw/ dateien/EZWINF101.pdf [letzter Zugriff am 26.2.2014].

62 Vgl. Irene Masing-Delic: Abolishing Death. A Salvation Myth of Russian Twentieth-Century, Stanford 1992; John E. Bowlt/Olga Matich (Hg.): Laboratory of Dreams. The Russian Avant-Garde and Cultural Experiment, Stanford 1996.

63 Vgl. Aleksandr Svjatogor: „Die biokosmische Poetik (1921)“, in: Groys/Hagemeister: Die Neue Menschheit (Anm. 9), S. 393-398, hier S. 393 f.

64 „Kreatorij Rossijskich i Moskovskich Anarchistov-Biokosmistov. Deklarativnaja rezolucija“, in: Biokosmist, 1 (1922), S. 1; deutsch zit. nach Boris Groys: „Unsterbliche Körper“, in: ders./Hagemeister: Die Neue Menschheit (Anm. 9), S. 8-67, hier S. 14.

65 Vgl. Jutta Scherrer: „Ein gelber und ein blauer Teufel.' Zur Entstehung der Begriffe ,bogostroitel'stvo" und ,bogoiskatel'stvo“", in: Forschungen zur osteuropäischen Geschichte, 25 (1978), S. 315-329; Raimund Sesterhenn: Das Bogostroitel'stvo bei Gor'kij und Lunačarskij bis 1909, München 1982. 
Einzelnen und vor allem den natürlichen Tod aus seiner Privatheit holte und einerseits in Lagern zur Disziplinierung, andererseits in Laboren zur Erforschung des (diesseitigen) ewigen Lebens organisierte und regulierte. ${ }^{66}$

Das 1926 in Moskau gegründete Institut für Bluttransfusion, dem der Physiologe, Schriftsteller und Politiker Aleksander Bogdanov (1873-1928) vorstand, strebte einen ,physiologischen Kollektivismus' durch Bluttransfusionen zwischen alten und jungen, kranken und gesunden Organismen an. Das Verfahren wechselseitiger Bluttransfusion hatte Bogdanov bereits 1908 in seinem utopischen Roman Der rote Stern (Krasnaja zvezda) beschrieben. Die nun in die Tat umgesetzte Vision zur Steigerung der Vitalität, zur Harmonisierung und Stabilisierung der Gemeinschaft durch Blutvermischung, fand durch Bogdanovs frühen Tod im Selbstexperiment ein schnelles Ende. ${ }^{67}$ Die Suche nach einer Lösung des Problems des Alterns und des Todes brach jedoch nicht ab.

Fedorovs Auftrag an die zukünftige Glaubensgemeinschaft, die Auferweckung der Toten, sollte das Fundament einer Theorie der Arbeitsorganisation bilden, die der Diplomat und Publizist Valerian N. Murav'ev (1885-1930/31) vorlegte. ${ }^{68}$ Darin hob er drei Bereiche kulturellen Handelns heraus, die in der Gesellschaft transformierend wirken sollen: Produktion, Politik, Genetik. ${ }^{69}$ Letztere definierte er als angewandte Wissenschaft der Auferweckung, worunter alle Verfahren zu verstehen seien, die darauf zielten, Leben zu erschaffen, neue Lebewesen zu kreieren oder alte aufzuerwecken. Die Notwendigkeit, nicht tote und abstrakte Kopien zu reproduzieren, sondern bisherige Formen durch vernünftige Organisation, Korrektur und Vervollkommnung zu nutzen, lasse die ,Genetik' zur ,Anastatik' werden, mit Murav'evs Worten: „die Kunst des Hervorbringens verwandelt sich in eine Kunst der Auferweckung ". ${ }^{70}$

Der Mensch - Denker, Schöpfer, Erbauer, Umgestalter, Anastatiker - war dazu bestimmt, projektiv-produktiv in einem weltverwandelnden Prozess zu agieren, der

66 Vgl. Boris Groys: „Unsterbliche Körper“ (Anm. 64), S. 10-14.

67 Vgl. Margarete Vöhringer: „Pfropfen. Aleksandr Bogdanovs zirkuläre Bluttransfusionen, Moskau 1924-1928", in: dies.: Avantgarde und Psychotechnik. Wissenschaft, Kunst und Technik der Wahrnehmungsexperimente in der frühen Sowjetunion, Göttingen 2007, S. 173-229.

68 Vgl. Murav'evs Schriften Ovladenie vremenem kak osnovnaja zadača organizacii truda (Die Beherrschung der Zeit als Grundaufgabe der Arbeitsorganisation, 1924), im Selbstverlag veröffentlicht, und Vseobšaja proizvoditel'naja matematika (Allgemeine Produktionsmathematik, posthum 1934). Murav'evs Postulat der „Beherrschung der Zeit" problematisierte nicht den Rationalisierungsfaktor der Arbeitsorganisation, den die von Aleksej Gastev (1882-1932) 1923 begründete Liga vremeni beispielsweise durch "Chronokarten“ zur Rechenschaftslegung über die tägliche Zeitplanung umzusetzen gedachte. Vielmehr war die Zeitfrage das Kriterium, das disparate Wissensfelder wie die Philosophie Henri Bergsons, Albert Einsteins Relativitätstheorie und die Laborwissenschaften zusammenführte (vgl. Murav'ev: Ovladenie vremenem kak osnovnaja zadača organizacii truda, Moskau 1924, Nachdruck nebst einführender Studie von Michael Hagemeister, München 1983, S. 10.). Von 1926 bis 1929, während seiner Mitarbeit an Gastevs Zentralinstitut der Arbeit, das zur Erforschung von Psychophysik und Psychophysiologie des Proletariats und deren Umerziehung im Zeichen einer neuen kollektiven Industriekultur diente, rezensierte und übersetzte Murav'ev ausländische Publikationen zur Arbeitswissenschaft.

69 Vgl. Murav'ev: Ovladenie vremenem (Anm. 68), S. 19.

70 Ebd., S. 109. 
den chaotischen und zufälligen Naturerscheinungen mit einer strukturierenden Ordnung begegnet. Der Politik und dem Gesetz obliege dabei die Sorge um die moralische Vervollkommnung der Menschen und der zwischenmenschlichen Beziehungen sowie die Etablierung eines Gesellschaftssystems, das die Menschen vereint und in ihrem gemeinsamen Handeln ausrichtet. Murav'ev folgte damit Fedorovs liturgischer Auferweckungspraxis und postulierte mit der entworfenen Produktionsgemeinschaft das Projekt einer globalen Gesellschaft (vsemirnoe obščestvo), welche die bestehenden Klüfte zwischen Völkern, Nationalitäten und Kontinenten überwinden und ihre naturwissenschaftlich-technischen Errungenschaften nicht in den Dienst des Todes, sondern des Lebens (eben der Auferweckung) stellen würde. ${ }^{71}$ Die Anastatik, die auf die geistig-spirituelle Vervollkommnung ebenso zielte wie auf eine grundlegende Änderung der Physis mittels „,anthropotechnischer“ und „anthropotheurgischer "Verfahren, ${ }^{72}$ grenzte er dabei vom naiv szientifisch-materialistischen Weg zum Neuen Menschen, dem Homunculus-Mythos, ab:

Produktion muss zur Genetik werden. [...] Produktion muss zu einer Produktion von Lebewesen gemacht werden, die dabei den derzeitigen halbherzigen Charakter der Übergangsphase, der Sterblichkeit, der Irrationalität und des Unbewussten aufgeben und ganz und gar zu bewussten Wesen werden müssen. Dann werden sie von den Gruppen, die sie erschaffen, permanent geboren und auferweckt werden. Diese Behauptung klingt deshalb sonderbar, weil wir uns an individuelle Labormethoden gewöhnt haben und uns beispielsweise die Schaffung des Menschen in einer wissenschaftlichen Werkstatt etwa so vorstellen, wie die Chemiker in Reagenzgläsern Homunkuli erzeugt haben. Tatsächlich muss der Prozess der Schaffung von Leben und somit der realen Überwindung der Zeit einen völlig anderen Charakter tragen. ${ }^{73}$

Murav'evs Theorie war ebenso von der zeitgenössischen medizinischen, biologischen und genetischen Forschung wie von jenem Gedankengut beeinflusst, das in den verschiedensten religiös-philosophischen Zirkeln und Vereinigungen der Moskauer Intelligenz und insbesondere unter den Anhängern Fedorovs zu Fragen der Vitalität und Unsterblichkeit kursierte. Mit der Idee, die anastatische Kunst als angewandte Leitwissenschaft einer globalisierten kosmischen Wirtschaft zu etablieren, reagierte er aber auch auf Diskussionen unter den sowjetischen Genetikern. Die Position der 1921 gegründeten Russischen Eugenischen Gesellschaft lautete, dass nur die wissenschaftliche Planung der menschlichen Fortpflanzung in der

71 Vgl. Murav'ev: „Vseobščaja proizvoditel'naja matematika“ (gekürzt), in: Semenova/Gačeva: Russkij kosmizm (Anm. 7), S. 190-210, hier S. 210.

72 Vgl. ebd., S. 203. Murav'evs ganzheitlicher Ansatz, der beiden Naturen des Menschen, der biologischen und der sozio-kulturellen, Rechnung trägt, weist Parallelen zur modernen philosophischen Anthropologie im Deutschland der 1920er Jahre (Max Scheler, Helmuth Plessner u.a.) auf. Seine Ausrichtung auf die körperliche Vervollkommnung verweist aber auch auf die sowjetische regulative Methodik der Psychotechnik.

73 Valerian N. Murav'ev: „Die Beherrschung der Zeit als Grundaufgabe der Arbeitsorganisation“ (Auszüge), in: Groys/Hagemeister: Die Neue Menschheit (Anm. 9), S. 425-455, hier S. 448. 
Lage sei, eine Selbstzerstörung der Zivilisation abzuwenden. ${ }^{74}$ Zudem werden Spekulationen aus der Mathematik erkennbar, wonach der Organismus durch eine mathematische Formel darstellbar und entsprechend regulierbar sei. ${ }^{75}$

Weniger spekulativ als Murav'evs Entwurf einer anastatischen Produktionskunst waren die physiologischen Experimente, die der Kardiologe und Pionier des kardiopulmonalen Bypasses Sergej Brjuchonenko (1890-1960) durchführte. 1920 konstruierte er in der Nachfolge von Kuljabko den „Autojektor“ - eine einfache HerzLungen-Maschine für die extrakorporale Blutzirkulation. ${ }^{76}$ Er erprobte ihn experimentell an einzelnen Organen, separierten Körperteilen und bei der Wiederbelebung von Organismen nach Kreislaufstillstand. Der Apparat wurde erstmalig 1926 auf dem Allrussischen Kongress der Pathologen vorgestellt, zwei Jahre später demonstrierte Brjuchonenko auf dem dritten Physiologenkongress der Sowjetunion einige Versuche. Diese wurden in dem Film Experiments in the Revival of Organisms (1940) dokumentiert und von westlichen Experten anerkennend kommentiert. ${ }^{77}$ $\mathrm{Zu}$ sehen ist eines der berühmten Dekapitationsexperimente Brjuchonenkos, die Mitte der 1920er Jahre in der europäischen Presse für Aufregung sorgten: Ein vom Rumpf abgetrennter Hundekopf wird an den Autojektor angeschlossen und auf

$74 \mathrm{Zu}$ Parallelen zum deutschen Eugenik-Diskurs vgl. Loren G. Graham: „Science and Values. The Eugenics Movement in Germany and Russia in the 1920s", in: The American Historical Review, 82 (1977) 5, S. 1133-1164; vgl. insbesondere Aleksandr S. Serebrovskijs (1892-1948) Plädoyer für eine „kommunistische Genetik“, die der ökonomischen Bedeutung von Genmaterial Rechnung trug, eine gentopographische Kartierung forderte und die Anwendung künstlicher Befruchtungstechniken zur Züchtung des sowjetischen Neuen Menschen vorsah: „Anthropogenetik und Eugenik in der sozialistischen Gesellschaft" (1929, Auszüge), in: Ludger Weß (Hg.): Die Träume der Genetik. Gentechnische Utopien von sozialem Fortschritt, Nördlingen 1989, S. 117-129. Dass sich Serebrovskijs Ansatz nicht als offizielle Leitlinie durchsetzen konnte, ist den generellen Auseinandersetzungen zwischen den Gruppierungen darwinistisch und lamarckistisch orientierter Biologen geschuldet, die in den 1920er bis 1930er Jahren zunehmend zur politischen Projektionsfläche wurden. Zunächst wurde der Darwinismus von staatlicher Seite protegiert, da er dem christlichen Schöpfungsmythos widersprach und den Atheismus untermauerte. In diesem Zusammenhang wurde die Züchtung von Mensch-Affen-Hybriden durch den Petersburger Biologen und Spezialisten für künstliche Besamung Il'ja I. Ivanov unterstützt. Mitte der 1930er geriet die Genetik zugunsten der Agronomie nach der quasi-larmackistischen Lehre Trofim D. Lysenkos (1898-1976) ins Abseits. Die Prämisse des Lysenkoismus, dass die Eigenschaften von Kulturpflanzen und anderen Organismen nicht durch Gene, sondern durch Umweltbedingungen bestimmt werden, wurde nicht nur in der sowjetischen Landwirtschaftslehre indoktriniert. Erst nach dem Sturz von Nikita S. Chruščev konnte die Irrlehre verworfen und in Theorie und Praxis revidiert werden.

75 Bereits 1911 begründete der Historiker, Soziologe und Anhänger der Gotterbauer Nikolaj Rožkov in Grundlagen einer wissenschaftlichen Philosophie (Osnovy naučnoj filosofii) die Möglichkeit, Verstorbene wiederherzustellen, mit der Annahme, dass die Verbindungen aller Elektronen innerhalb eines menschlichen Organismus durch eine mathematische Strukturformel (formula stroenija) vollständig darstellbar und beliebig manipulierbar seien.

76 Igor E. Konstantinov/Vladimir V. Alexi-Meskishvili: „Sergei S. Brukhonenko. The Development of the First Heart-Lung Machine for Total Body Perfusion“, in: The Annals of Thoracic Surgery, 69 (2000), S. 962-966.

77 Vgl. http://www.archive.org/details/Experime1940 [letzter Zugriff am 26.2.2014]. Der britische Physiologe John B. S. Haldane - ein führender Vertreter der Populationsgenetik und Evolutionsbiologie sowie Kommunist - führt in den Film ein, und während der Dokumentation spricht der US-amerikanische Physiologe Walter B. Cannon. 
Reizfähigkeit überprüft. ${ }^{78}$ Dieser Laborversuch bildete die Vorstufe zum ebenfalls dokumentierten Reanimationsexperiment: Ein Versuchstier wird zunächst (unter Narkose) in den klinischen Tod überführt, d.h. der Kreislauf durch Blutablass zum Stillstand gebracht, nach zehn Minuten an den Autojektor angeschlossen und reanimiert. Die propagandistische Verklärung des technologischen Fortschritts in der Sowjetunion wird in der Abschlussszene, in der das unbeschadete Weiterleben der Versuchstiere nach der Wiederbelebung suggeriert wird, besonders deutlich.

Der künstliche Blutkreislauf sowie das Am-Leben-Erhalten von Körperteilen und von Organen außerhalb eines lebenden Organismus sind grundlegende Techniken der Transplantationsmedizin und der Herzchirurgie. In den 1920er Jahren verkörperte Brjuchonenkos Apparat jedoch die schaurig-faszinierende Macht der technologischen Auferweckung. Sein Schöpfer diente der Wissenschaftsphantastik (naučnaja fantastika), der russischen Science-Fiction-Literatur, als Prototyp für den experimentierenden Schöpfer des lebendigen rumpflosen Kopfes - so in Aleksandr R. Beljaevs (1884-1942) Roman Der Kopf des Professor Dowell (Golova professora Douelja, 1925). ${ }^{79}$ Der sprechende Kopf, der hier als biologische Denk- und Informationsmaschine dargestellt wird, knüpft an eine lange Tradition vitaler und rollender Köpfe an. ${ }^{80}$ Brjuchonenko selbst zeigte sich an einer Popularisierung seiner Versuche durch die Belletristik interessiert. Dem Schriftsteller Michail A. Bulgakov, der in seiner Novelle Hundeherz (Sobače serdce, 1926) der Phantastik damaliger Trans-

78 Sergej S. Brjuchonenko/Sergej I. Čečulin: «Expériences acec la tête isolée du chien», in: Journal de phisiologie et de pathologie générale, 27 (1929), S. 31-45. Von Brjuchonenkos Experimenten dieser Art berichtet bspw. bereits das Berliner Tageblatt vom 17. März 1929. Darin wird auch eine Passage aus dem Brief des englischen Schriftstellers George Bernard Shaw an eine Berlinerin abgedruckt, der nicht ohne Ironie die Experimentierkultur in Russland kommentiert; vgl. „Shaw will sich köpfen lassen, wenn ... Ein Privatbrief des Dichters über ein neues, abschreckendes Tierexperiment", in: Berliner Tageblatt, 130, 17.3.1929, 1. Beiblatt. Transplantationsversuche mit Hundeköpfen - einem Hund wurde ein zweiter Kopf verpflanzt, der damit sechs Tage lang lebte, bevor man ihm das Transplantat wieder abnahm - unternahm Mitte der 1950er der sowjetische Physiologe Vladimir P. Demichov (1916-1998), ein Experte für Herz- und Lungentransplantationen, der auf diesem Gebiet eine wegweisende Dissertation vorlegte: Experimental transplantation of vital organs (1960), aus dem Russischen von Basil Haigh, New York 1962.

79 In der populären Verfilmung von Beljaevs Roman durch Leonid Menaker unter dem Titel Das Testament des Professors Douel (Zaveščanie Professora Douelja, 1984) wird nicht nur der vitale sprechende Kopf inszeniert, sondern auch Kopftransplantationen thematisiert, die der amerikanische Neurochirurg Robert White in den 1970er Jahren an Rhesusaffen durchgeführte; vgl. auch Nikolai Krementsov: „Off with your Heads. Isolated Organs in Early Soviet Science and Fiction“, in: Studies in History and Philosophy of Biological and Biomedical Sciences, 40 (2009) 2, S. 87-100.

80 Angefangen vom mythischen Orakelkopf über die mittelalterliche Rechenmaschine und die romantische Tradition des Automaten werden bis heute die modernen oder futuristischen Steuerungszentralen als vitale Köpfe dargestellt. Die Kulturgeschichte ,rollender Köpfe', von der Kopftrophäe bis zur Serialisierung der Dekapitation durch die französische Guillotine, zeigt, dass nicht zuletzt die Populärmythologie das Interesse an derartigen Vitalitätsexperimenten verstärkt hat. Nachdem Neurophysiologen die Reflexe von Köpfen guillotinierter Verbrecher untersuchten, rückte die Vitalität des rumpflosen Kopfes verstärkt in die Aufmerksamkeit von Physiologie, Medizintechnik, Informationstechnologie und Kunst. 
plantationen zu Transformationszwecken bereits Ausdruck verliehen hatte, ${ }^{81}$ offerierte er jedenfalls das Laborgeschehen als „fertiges Material für ein Theaterstück“ 82

Das prominenteste Beispiel für die fortschreitende Experimentalisierung des Lebens ist die Inszenierung des ,unsterblichen Lenin', der, konserviert im Alter von 53 Jahren, noch heute an der Kreml-Mauer liegt. Als Vladimir Il'ič 1924 starb, schlugen die Gotterbauer Bogdanov und Leonid B. Krasin (1870-1926), ein Chemie- und Sprengstoffexperte sowie Anhänger von Bachmet'evs Anabiose-Theorie, die Kryonisierung des Toten vor - eine Vorstufe zur physischen Unsterblichkeit Lenins, den es galt, in der Zukunft aufzuerwecken. Es kam jedoch anders: Lenins Gehirn diente bekanntlich Oskar Vogt, in mikroskopische Einzelpräparate zerlegt, zur Forschung am ,genialen' Sowjet-Gehirn - dem grundlegendsten Baustein des zu erschaffenden Neuen Menschen. ${ }^{83}$ Sein Körper aber wurde einbalsamiert und in einem Mausoleum am Moskauer Kreml ausgestellt. Damit knüpfte man an die christlich-orthodoxe Tradition an, wonach unverweste Leichname von der Heiligkeit des Verstorbenen zeugten (zeitgleich wurden Gräber von orthodoxen Heiligen geöffnet, um durch den Anblick der zersetzten körperlichen Überreste deren Heiligkeit als Betrug zu entlarven) und wählte als Ort die von Fedorov zur Auferweckung der Toten vorgeschlagene Kultstätte. Auch die Entdeckung des Grabes von Pharao Tutenchamun im Jahre 1922 inspirierte zu diesem Entschluss. ${ }^{84}$ Der Kubus, den der Architekt Aleksej V. Ščusev (1873-1949) als Grundform seines Mausoleums wählte, galt als sowjetisches Gegenstück zur Pyramide. Darin konnte Lenin, anders als bei einer Kryonisierung, wie in einem Dornröschen- oder Schneewittchenschlaf präsentiert und vom Volk verehrt werden - nach einem vom Staat dik-

81 Der Text konnte allerdings erst 1968 in einer russischen Exilzeitschrift und 1987 erstmalig in der Sowjetunion veröffentlicht werden. Bulgakov lässt einem Moskauer Gassenhund Samendrüse und Hypophyse eines verstorbenen Verbrechers und Trinkers einpflanzen - eine Anspielung auf das sowjetische Experiment zur Erschaffung des Neuen Menschen, das in seinem konkreten Ausmaß hinter den alludierten Versuchen im Labor des Doctor Moreau aus Herbert George Wells' phantastischem Roman von 1896 und die Verjüngungskuren des russischen Arztes Sergej Voronov, der in den 1920er Jahren Männern in Paris Affenhoden transplantierte, zurücktritt; vgl. Renate Lachmann: „Arkanisierung von Wissen im phantastischen Text“, in: dies./Stefan Rieger (Hg.): Text und Wissen. Technologische und anthropologische Aspekte, Tübingen 2003, S. 227-242, hier S. 238-241.

82 Vgl. den Tagebucheintrag vom 1. November 1933, den Bulgakovs Frau vornahm: „Anruf des Schriftstellers Budanzew [Sergej F. Budancev]: Der Physiologe Brjuchonenko, der an dem Problem der Belebung von toten Organismen arbeitet und Versuche mit abgetrennten Hundeköpfen macht, möchte M. A. [Bulgakov] sehr gerne kennenlernen. [...] Zwei Stunden später kam Brjuchonenko, erzählte von der Arbeit seines Instituts, meinte, das sei fertiges Material für ein Theaterstück, lud uns ein. Zeigte uns Beispiele dreidimensionaler Zeichnungen, die er mitgebracht hatte." (Jelena Bulgakowa: Margarita und der Meister: Tagebücher - Erinnerungen. Tagebücher 1933-1940, aus dem Russischen von Antje Leetz/Ottokar Nürnberg, Berlin 1993, S. 21 f.)

83 Vgl. Torsten Rüting: Pavlov und der Neue Mensch. Diskurse und Disziplinierung in Sowjetrussland, München 2002, S. 169-213; Michael Hagner: „The Pantheon of Brains“, in: Bruno Latour/Peter Weibel (Hg.): Making Things Public, Cambridge 2005, S. 126-131.

84 Mit 7500 Dollar sei Lenins Einbalsamierung weitaus günstiger als der Pharaonenkult der Ägypter, sollen die Konservatoren von Lenins Körper in der ersten internationalen Pressekonferenz im August 1924 gescherzt haben. Zu den Hintergründen von Lenins Konservierung vgl. Nina Tumarkin: Lenin Lives! The Lenin Cult in Soviet Russia, Cambridge 1997. 
tierten Szenario. Der Personenkult verbannte den Tod aus der Sprache: Das Begräbniskomitee wurde in „Komitee für die Verewigung des Andenkens an V. I. Ul'janov (Lenin)“ umbenannt, und 1955 verlegte man die Feierlichkeiten zu Lenins Todestag im Zeichen symbolischer Lebensbejahung auf seinen Geburtstag.

Ein Beispiel, wie sich schließlich eine Auferweckung abspielen könnte, gibt der Futurist Vladimir V. Majakovskij (1893-1930). In seinem Theaterstück Die Wanze (Klop, 1928) entwarf er dafür eigens ein „Institut für menschliche Auferweckung“. Sein Held, der mitsamt einer Wanze eine Feuerkatastrophe in gefrorenem Löschwasser ,überlebte', sollte fünfzig Jahre später wiederbelebt werden - natürlich erst nach Gewerkschaftsdebatten über hygienische und andere Gefahren, die mit der Auferweckung dieser ,Fossile 'einer längst vergangenen Epoche einhergingen. Doch wirklich in Gefahr sind bei dieser Prozedur allein die Auferweckten, denn diese halten, wie Majakovskijs Szenario nahelegt, den Lebensgewohnheiten und Überlebensstrategien der Zukunftsgesellschaft nicht stand.

Die im ersten Drittel des 20. Jahrhunderts florierenden Diskurse und Praktiken der Auferweckung, von Fedorovs kosmotellurisch wiederbelebtem KunstWerk Mensch über die Schöpfungsmacht und suggestive Kraft des Wortes bis hin zur spekulativen anastatischen Produktion, zur biomedizinischen Reanimation und zum Unsterblichkeitskult um Lenin, rufen biblische Mysterien und Erweckungsrituale vergangener Zeiten ins Gedächtnis - mit dem Unterschied, dass die modernen Techniken und Technologien die Körper-/Geist-Auferweckung und Erhebung nun buchstäblich inszenierten. Das Leben vom Tode her zu denken, bedeutete für die russische Moderne, dass die Rede von der ,Auferweckung in (Religions-)Philosophie, Wissenschaft, Kunst und Kulturpolitik programmatisch war und nach 1917 zunehmend ideologisiert wurde. Die weltanschaulichen Pole des weitgefächerten Spektrums entsprechender Rhetoriken liegen zwischen dem undogmatisch christlich-orthodoxen Denken der Kosmisten mit ihrer anthropologischen Utopie von der Auferweckung der Toten einerseits und der Tabuisierung des Todes im Marxismus-Leninismus, der einen diesseitigen Optimismus propagierte und diesen auf die Erschaffung einer unsterblichen sowjetischen Menschheit projizierte, andererseits. Beide Pole haben einander aber auch, wie die Haltung der Gotterbauer nahelegt, durchdrungen. Gemein war ihnen der Rückgriff auf die neuen Errungenschaften von Wissenschaft und Technik, nicht nur im Hinblick auf eine Technikgläubigkeit, sondern in der Rolle, die der Mensch in den Erklärungsansätzen einer neuen Anthropo(sozio)genese und deren sozialtechnologischen Umsetzungsversuchen spielte.

Berdjaev, der dem ethischen Aspekt der Technik- und Technologieentwicklung nach 1900 in seinem in Paris veröffentlichten Essay Der Mensch und die Technik (Čelovek i mašina, 1933) nachging, schlussfolgerte, dass es zur Neuregulierung des sozialen Lebens unter den neuen technischen Voraussetzungen auch eines neuen religiösen Bewusstseins bedürfe. Gerade in diesem Zusammenhang stellte er Fedorovs Entwurf einer neuen christlichen Anthropologie heraus, die aus seiner Sicht mit der aufkommenden technokratischen Eschatologie - einer auf den Kopf ge- 
stellten christlichen Eschatologie - nichts gemein habe. ${ }^{85}$ Ergänzend müsste man hinzufügen: auch nicht mit der kommunistischen Eschatologie, obwohl, wie bereits Berdjaev anmerkte, gewisse Parallelen gezogen werden können. Der christliche Auftrag zur Selbsttransformation, wie Paulus ihn formulierte: „zieht den neuen Menschen an, der nach Gott geschaffen ist" (Brief an die Epheser 4,24), war im sowjetischen Diskurs nicht zuletzt durch die Debatten und eingeschlagenen Wege in Biologie, Genetik und Physiologie derart radikalisiert worden, dass er ins Gegenteil umschlug. Die Neufiguration, die der Mensch als Wissenschaftler-Künstler

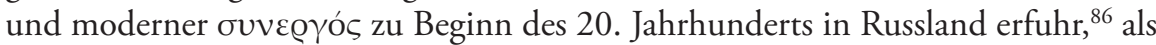
es darum ging, die christlich-orthodoxe Gesellschaft im Zuge der fortschreitenden technologischen Revolution und bahnbrechender naturwissenschaftlicher Erkenntnisse zu modernisieren, wurde spätestens mit den ideologischen Umwertungen und Ideologisierungen der Sowjetmacht ambivalent. Das bleibt auch der Fall für das Nach- und Wiederaufleben von Auferweckungstechniken und SynergieKonzepten, ${ }^{87}$ die sich, wie eingangs skizziert, vor dem Hintergrund neuer gesellschaftlicher Transformationsprozesse für das 21. Jahrhundert bereits angekündigt haben.

85 Nicolas Berdjajew: Der Mensch und die Technik, Berlin/Bielefeld 1949, S. 57-64.

86 Vgl. Tatjana Petzer: „Kultakte der Wissenschaft. Synergie und Synthese im russischen Kosmismus", in: Nadežda Grigor'eva/Schamma Schahadat/Igor' Smirnov/Irina Wutsdorff (Hg.): Das Konzept der Synthese im russischen Denken. Künste - Medien - Diskurse (Wiener Slawistischer Almanach, Sonderband 76), München/Wien 2010, S. 171-192.

87 In der Retrospektive werden die Entwürfe der russischen Kosmisten zunehmend mit einem Brückenschlag zur modernen Synergetik, verstanden als naturwissenschaftliches und weltanschauliches Paradigma, rezipiert; vgl. Aleksandr S. Kamenev: „Sinergetičeskie aspekty učenij russkih kosmistov" (2007), unter: http://www.mgpu.ru/download.php?id=4110 [letzter Zugriff am 26.2.2014]; Elena N. Knjazeva: „Idei russkogo kosmizma i sinergetiki“, in: Trudy Ob”edinennogo Naučnogo centra problem kosmičeskogo myšlenija, Bd. 1, hg. vom Internationalen Roerich Zentrum, Moskau 2007, S. 228-255. 